\title{
Comparison of population genetic structures of common wild rice (Oryza rufipogon Griff.), as revealed by analyses of quantitative traits, allozymes, and RFLPs
}

\author{
H-W Cai ${ }^{1,2}$, X-K Wang ${ }^{2}$ and H Morishima ${ }^{1,3}$ \\ ${ }^{1}$ National Institute of Genetics, Mishima 411-8540, Japan; ${ }^{2}$ China Agriculture University, Beijing 100094, China
}

We investigated genetic diversity among and within natural populations of Asian common wild rice, Oryza rufipogon, from three different classes of data: quantitative traits, allozymes, and restriction fragment length polymorphisms (RFLPs). The seven populations examined showed polymorphism to varying degrees. The amount of intrapopulation variability appeared to be influenced not only by breeding system but also by the evolutionary history of each population. Interpopulation differentiation was clear, but different classes of data elucidated different patterns. Quantitative traits revealed ecotype differentiation into perennial and annual types of population, whereas allozyme and RFLP analyses revealed geographical differentiation among populations. These results suggest that the diversity patterns shown by quantitative trait analysis reflect mainly the occurrence of adaptive differentiation in response to habitat conditions and that those shown by allozyme and RFLP analyses reflect mainly the effect of isolation by distance. Population differentiation parameters $\left(F_{\mathrm{ST}}\right)$ were highly variable among loci in allozymes as well as in RFLPs. Heredity (2004) 92, 409-417, advance online publication, 3 March 2004; doi:10.1038/sj.hdy.6800435

Keywords: population genetic structure; wild rice; quantitative traits; allozyme; RFLP; population differentiation

\section{Introduction}

Population genetic structure or distribution of genetic variation among and within natural populations is a major concern in evolutionary genetics. In early studies, morphological traits were the only sources of evidence that could be used to elucidate population structure. However, during the last two decades molecular approaches have become a standard means of determining the genetic architecture of natural populations.

Phenotypic traits of either a continuous or discrete nature are substantially affected by natural selection, and their patterns of variation therefore largely reflect adaptive differentiation. On the other hand, it is usually assumed that a considerable portion of molecular variation is selectively neutral and that the molecular-clock hypothesis (Kimura, 1968) holds, although this assumption may not be always true, as argued by Koehn et al (1983) and Karl and Avise (1992). Differences between the patterns detected by allozymes and the use of various DNA marker techniques such as analyses of restriction fragment length polymorphism (RFLP), random amplified polymorphic DNA (RAPD), and simple sequence repeats (SSR) might be of concern only at a level at which

Correspondence: H-W Cai. Current Address: Japan Grassland Farming and Forage Seed Association, Forage Crop Research Institute, 388-5 Higashiakata, Nishinasuno, Tochigi 329-2742, Japan.

E-mail: hcai@jfsass.or.jp

${ }^{3}$ Current address: Department of Agriculture, Tokyo University of Agriculture, Funako 1737, Atsugi, Kanagawa 243-0034, Japan Received 30 December 2002; accepted 8 January 2004; published online 3 March 2004 genetic variation can be dissected: allozyme variation detects polymorphism at protein coding regions, whereas molecular variation reflects differences directly at the DNA level in both coding and noncoding regions.

Biosystematic and population studies conducted in various plant and animal species have shown that the results obtained by quantitative trait and molecular marker analyses are not always concordant (Podolsky and Holtsford, 1995; Bonnin et al, 1996; Latta and Mitton 1997; Reed and Frankham 2001). If the materials are exactly the same and the methods used are appropriate for their respective approaches, but the results differ, then any inconsistency suggests that the underlying evolutionary forces differ among different types of genetic variation. Therefore, there is a need to clarify which aspects of the entire genome can be revealed by using different types of genetic data.

The common wild rice, Oryza rufipogon Griff., is widely distributed in the tropical and subtropical regions of Asia and Oceania and is considered to be the progenitor of cultivated rice, O. sativa L. (see, for review, Oka, 1988). It contains a large amount of intraspecific genetic variability and tends to be differentiated into two ecotypes: partly outbreeding perennial and predominantly inbreeding annual. The two types are adapted to different habitat conditions and are characterized by contrasting morphologies, propagating methods and mating systems (Oka and Morishima, 1967; Sano and Morishima, 1982; Morishima et al, 1984). The population genetic structures of Indian and Thai populations of O. rufipogon have been studied by the analysis of quantitative traits (Morishima and Oka, 1970) or life-history traits and allozymes 
(Barbier, 1989; Morishima and Barbier, 1990). Chinese populations of $O$. rufipogon were investigated by the analysis of allozymes (Gao et al, 2000), RAPD (Ge et al, 1999), and SSR (Gao et al, 2002).

Our objective was to assess genetic diversity among and within natural populations of O. rufipogon collected from a broad area over the distribution range of this species in Asia. We compared the population structure as revealed by: (a) quantitative trait analysis, (b) allozyme analysis, and (c) nuclear DNA RFLP analysis. We discuss the evolutionary forces causing the different patterns of population differentiation resulting from the analysis of these three different classes of data.

\section{Materials and methods}

\section{Plant materials}

Seven population samples of O. rufipogon were taken from genetic stocks preserved at China Agriculture University, China, and the National Institute of Genetics, Japan. Samples were collected from China (3), Thailand (2), India (1), and Indonesia (1) (Figure 1). Basic information on each population is given in Table 1. From our field observations, population NE3 was a typical annual type propagating by seeds; NE88, W1981, and W120 seemed to be perennial, propagating mainly by vegetative means (clones); and YJ, DX, and GG seemed to be weakly perennial, propagating by both clones and seeds. In four populations (YJ, GG, W1981, and W120), the individuals examined were first-generation plants

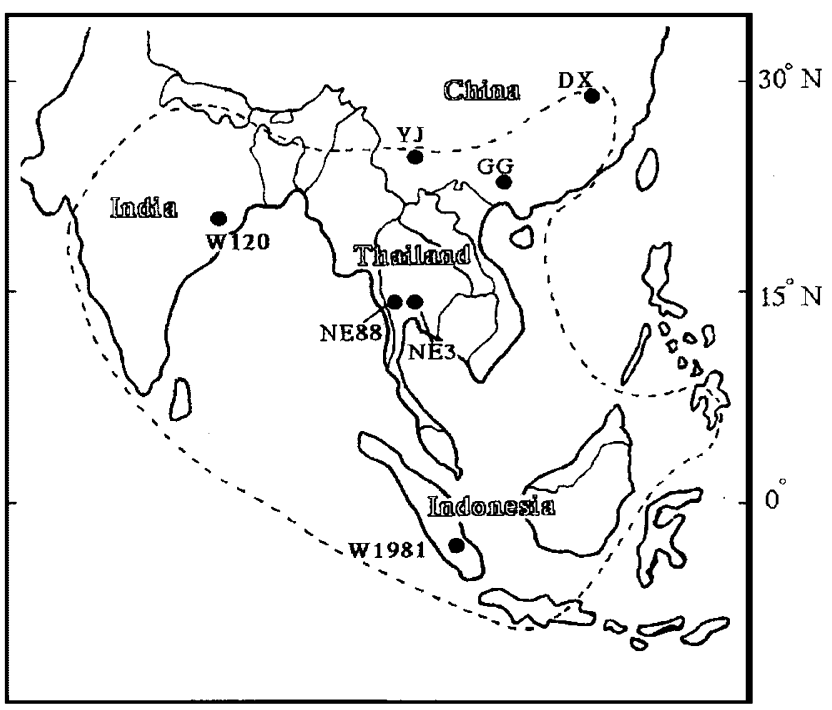

Figure 1 Site map of the seven populations studied. Dotted line shows the distribution range of O. rufipogon in Asia. derived from the original seeds collected at each site. In the other three populations (DX, NE3, and NE88), selfed progeny of first-generation plants derived from the original seeds collected on an individual plant basis were examined. Population GG (Guangxi Province, China) was adjacent to cultivated rice fields and was apparently susceptible to introgression by cultivar genes. Other populations were isolated from cultivated rice fields to varying degrees.

\section{Quantitative trait analysis}

Seeds of the seven populations were sown, and a total of 292 seedlings were transplanted into a paddy plot in a greenhouse at the National Institute of Genetics, Mishima, Japan, in 1994 July. The following 11 morphological and physiological traits were evaluated on an individual basis: plant height, panicle number, panicle length, spikelet number per panicle, awn length, seed fertility, shoot-regenerating ability, root-regenerating ability, dry weight of stem and leaf at maturity, dry weight of small tillers developed after heading, and heading date. Regenerating ability was assessed as follows: several basal stem segments with nodes were cut at the time of maturity and placed in moistened sand at $30^{\circ} \mathrm{C}$. After 5 days, the degree of development of adventitious roots was given a value of $0,1,2$, or 3 (rootregenerating ability), and the number of newly emerging shoots was counted (shoot-regenerating ability). The Indian population W120 was excluded from the trait analysis because the plants were grown in another greenhouse.

\section{Allozyme assay}

At the tillering stage, leaf samples were taken from each plant and analyzed for 29 isozyme loci. Cat1, Sdh1, Amp1, Amp2, Amp3, Amp7(t), Pgd1, Pgd2, Pgi1, Pgi2, Pgi3, Pox2, Est9, and EstS(t) were assayed by a starch gel system (Ishikawa et al, 1989), and Est1, Est2, Est3, Est5, Est10, Est12, Est14, Acp1, Acp2, Acp3, Acp5(t), Acp6(t), Mal1, $\operatorname{Mal5}(\mathrm{t})$, and Mal6(t) were assayed by the SDS-PAGE electrophoresis system (Cai et al, 1992). Newly identified loci (our unpublished data) are designated 'tentative' with a (t).

\section{RFLP assay}

Nuclear DNA was extracted with liquid nitrogen from fresh leaves sampled from each plant at the tillering stage and digested with four restriction enzymes, HindIII, EcoRI, DraI, and BamHI. DNA digestion, electrophoresis, and Southern blotting were carried out according to the method of McCouch et al (1988). DNA hybridization was performed with the $\mathrm{ECL}^{\mathrm{TM}}$ direct nucleic acid labeling and detection systems (Amersham,

Table 1 Basic information on the seven populations examined

\begin{tabular}{lclll}
\hline Population code & No. of plants examined & Collection site & Distance from rice fields & Propagation system \\
\hline DX & 54 & Dongxiang, Jiangxi, China & Far & Weakly perennial (ratoon and seeds) \\
YJ & 14 & Yuanjiang, Yunnan, China & Far & Weakly perennial (ratoon and seeds) \\
GG & 68 & Guigang, Guangxi, China & Adjacent & Weakly perennial (ratoon and seeds) \\
NE3 & 74 & Saraburi, Central Plain, Thailand & ca. 200 m & Annual (seeds) \\
NE88 & 46 & Hingkon, Central Plain, Thailand & ca. 100 m & Perennial (mainly ratoon) \\
W1981 & 22 & Palembang, Sumatra, Indonesia & Far & Perennial (mainly ratoon) \\
W120 & 14 & Cuttack, Orissa, India & ca. 100 m & Perennial (mainly ratoon) \\
\hline
\end{tabular}


Little Chalfont, Buckinghamshire, UK). Probes (RG\# and $\mathrm{G \#}$ - rice genomic clones; RZ\# - rice cDNA clones; $\mathrm{BCD \#}$ - barley cDNA clones, and CDO\# - oat cDNA clones) were provided by Dr T Sasaki, Rice Genome Program, STAFF Institute, Tsukuba, Japan and Dr SR McCouch, Cornell University, Ithaca, NY, USA. These clones are known to correspond to loci mapped to 12 rice chromosomes. In all, 15 probe-enzyme combinations were used.

\section{Data analysis}

The amount of intrapopulation diversity for quantitative traits was represented by standard deviation. To assess the degree of population differentiation at the phenotype level, the variance component among populations divided by the sum of variance components among and within populations was computed for each trait $\left(P_{\mathrm{ST}}\right)$. For allelic diversity within populations in terms of allozymes and RFLPs, genetic parameters such as average gene diversity $(H)$, proportion of polymorphic loci, average number of alleles per locus, and inbreeding coefficient $\left(F_{\mathrm{IS}}\right)$ were calculated from all loci examined. The population parameters $H_{\mathrm{T}}$ (gene diversity in whole population), $H_{\mathrm{s}}$ (gene diversity within a population) and $F_{\mathrm{ST}}$ (population differentiation) were estimated for each isozyme and RFLP locus. Further, the genetic distances (Nei, 1972) between the seven populations were computed. To elucidate the overall pattern of population differentiation, individual data on quantitative traits, allozymes, and RFLPs were analyzed by the same multivariate technique (factor analysis) using Statistica 3.0 software (StarSoft Technologies, Inc., Spokane, WA, USA).

\section{Results}

\section{Quantitative traits}

Means and standard deviations for the 11 quantitative traits in six populations (excluding W120 grown under different condition) are shown in Table 2. The annual population NE3 markedly differed from other perennial populations in many traits. It had shorter stature, more panicles, longer awns, higher seed fertility, lower shootregenerating ability, and less development of new tillers after maturity. The other five populations, in particular typical perennial populations (NE88 and W1981), showed the opposite trend. These contrasting trait associations are characteristic of the annual and perennial types of O. rufipogon, respectively (Oka and Morishima, 1967; Sano and Morishima, 1982). The Chinese population DX, which was supposed to be weakly perennial, showed more vigorous development of new tillers after heading than the other perennial populations, suggesting its unique mode of vegetative propagation.

As shown by the standard deviations given in Table 2, the introgressed population GG and the perennial population NE88 showed greater within-population variation than the others in many traits. The parameters of population differentiation $\left(P_{\mathrm{ST}}\right)$ for various traits (Table 2) varied in a relatively narrow range from 0.262 to 0.426 , with the exception of that for panicle length (0.023).

To elucidate the pattern of variation among and within populations on the basis of all the traits, data for all individuals were analyzed by factor analysis. The first and second factors explained 38.4 and 22.5\%, respectively (cumulative contribution, 60.9\%), of the whole multivariate variation. The traits mainly contributing to the first factor were shoot-regenerating ability (factor loading, 0.87), plant height (0.77), awn length (-0.71), and seed fertility $(-0.65)$, and those contributing to the second factor were spikelet number per panicle (0.85), panicle length (0.74), and leaf and stem weight at maturity (0.73).

The scatter diagram of all individuals, as defined by the first and second factors, is shown in Figure 2. The plants belonging to each population tended to form respective clusters, although the three Chinese populations, DX, YJ, and GG, showed overlapping distributions. NE3 (annual type) and NE88 (perennial type) collected in the same locality in Thailand were clearly separated along the first factor axis, suggesting that this axis represents differentiation toward perennial and annual types. The three Chinese populations were scattered between the annual NE3 and perennial NE88, indicating that they possess intermediate characteristics between annual and perennial, in accordance with our field observations. Plants with larger scores for the second factor (scattered in the upper part) were supposed to have large seed productivity as well as vegetative vigor, judging from the traits contributing to the second factor. They were most probably the derivatives of natural hybridization with cultivated rice.

Table 2 Mean values and SD (in parentheses) of 11 quantitative traits in six populations, and a parameter for population differentiation $\left(F_{\mathrm{ST}}\right)$

\begin{tabular}{|c|c|c|c|c|c|c|c|}
\hline \multirow[t]{2}{*}{ Character } & \multicolumn{6}{|c|}{ Population (propagating system ${ }^{*}$ ) } & \multirow[t]{2}{*}{$\mathrm{P}_{S T}$} \\
\hline & $D X(W P)$ & $Y J(W P)$ & $G G(W P)$ & NE3 $(A)$ & NE88 $(P)$ & W1981 (P) & \\
\hline Plant height $(\mathrm{cm})$ & $127(21.8)$ & $152(25.3)$ & $158(26.4)$ & $115(13.1)$ & $214(42.0)$ & $167(33.2)$ & 0.400 \\
\hline Panicle number per plant & $17.3(3.5)$ & $4.9(2.0)$ & $6.1(4.1)$ & $13.5(6.6)$ & $4.6(4.0)$ & $3.7(2.4)$ & 0.294 \\
\hline Panicle length $(\mathrm{cm})$ & $17.3(2.8)$ & $17.5(3.2)$ & $19.0(4.6)$ & $18.0(1.8)$ & $20.1(4.7)$ & $17.5(1.7)$ & 0.023 \\
\hline Spikelet number per panicle & $32.6(12.0)$ & $51.4(12.4)$ & $45.4(32.7)$ & $64.6(11.5)$ & $58.6(24.5)$ & $49.5(11.8)$ & 0.231 \\
\hline Awn length $(\mathrm{mm})$ & $4.9(0.8)$ & $5.5(0.6)$ & $6.1(1.2)$ & $9.3(1.0)$ & $5.9(1.4)$ & $4.3(0.7)$ & 0.426 \\
\hline Seed fertility $(\%)$ & $24.1(14.4)$ & $15.6(14.3)$ & 9.5 (11.8) & $43.5(19.1)$ & $17.5(19.9)$ & 6.7 (11.3) & 0.278 \\
\hline Root-regenerating ability (index) & $0.52(0.5)$ & $0.84(0.6)$ & $1.68(0.8)$ & $0.86(0.5)$ & $1.76(0.8)$ & $0.82(0.6)$ & 0.262 \\
\hline Shoot-regenerating ability (no. of shoots/stem cut) & $0.60(0.3)$ & $0.90(0.2)$ & $0.80(0.2)$ & $0.10(0.2)$ & $0.90(0.2)$ & $0.80(0.4)$ & 0.418 \\
\hline Leaf and stem dry weight $(\mathrm{g})$ & $16.1(8.0)$ & $17.1(8.7)$ & $28.3(27.4)$ & $24.7(11.9)$ & $39.7(29.5)$ & $25.7(16.4)$ & 0.389 \\
\hline Dry weight of tiller developed after heading (g) & $3.1(1.7)$ & $0.6(0.6)$ & $0.5(0.6)$ & $0.2(0.5)$ & $1.4(1.1)$ & $1.2(1.0)$ & 0.374 \\
\hline Days from seeding to heading & $69(7.3)$ & $71(5.0)$ & $69(6.7)$ & $70(3.9)$ & $103(7.3)$ & $93(2.8)$ & 0.381 \\
\hline
\end{tabular}

*WP: weakly perennial; P: perennial; A: annual. 


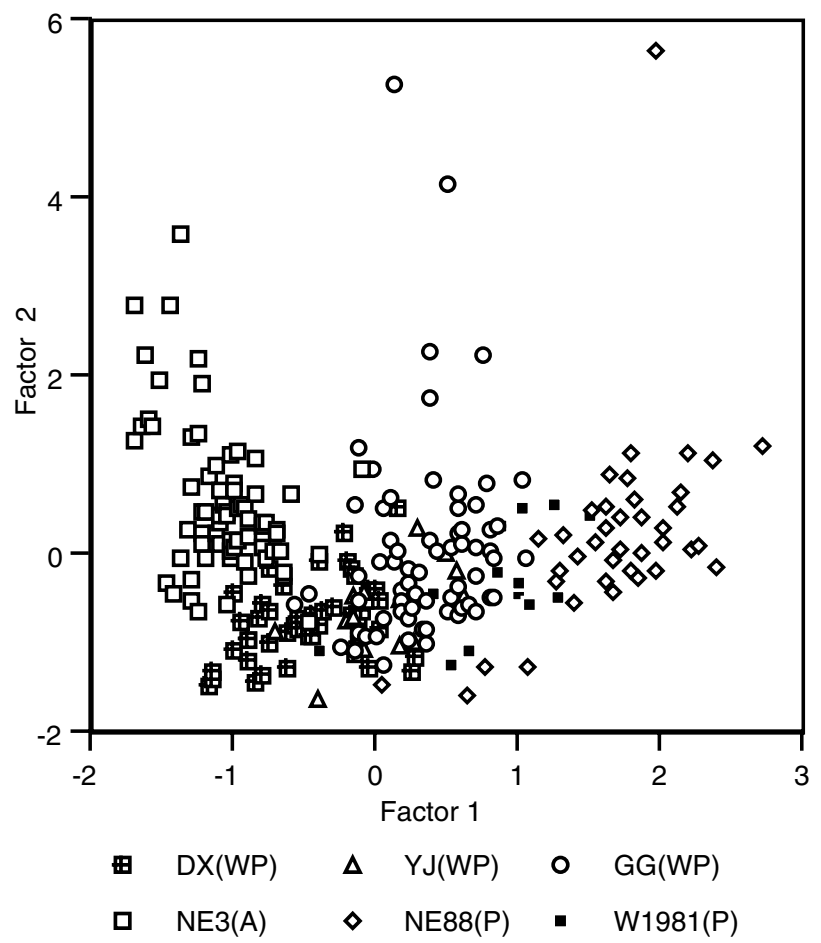

Figure 2 Scatter diagram of the plants belonging to six populations on the first and second factor scores, based on quantitative traits.

\section{Allozyme diversity}

Of the 29 isozyme loci examined, Acp1 and Mal1 were monomorphic and the other 27 loci were polymorphic in the present materials. So far, we have detected polymorphism at $A c p 5(\mathrm{t}), \operatorname{Acp} 6(\mathrm{t}), \operatorname{Mal5}(\mathrm{t})$, and Mal6(t) only in O. rufipogon and not in O. sativa (our unpublished data). The allele frequencies for the 27 polymorphic loci in each population are given in Table 3 , together with the population parameters $H_{\mathrm{T}}, H_{\mathrm{S}}$, and $F_{\mathrm{ST}}$ for each locus. At some loci, such as Amp1, Cat1, and Est14, the allele frequencies seemed to change dramatically between two (DX and YJ) or three (DX, YJ, and GG) of the Chinese populations and the remaining populations collected in tropical regions. Interestingly, Cat1 (Second, 1982) and Est14 (our unpublished data) are known as diagnostic loci for distinguishing Indica and Japonica types of $O$. sativa, and the alleles found in Chinese populations at high frequencies (Cat ${ }^{2}$ and Est141) are 'Japonica-specific alleles' (Second 1985, our unpublished data).

Estimates of genetic parameters of intrapopulation diversity, such as average gene diversity, proportion of polymorphic loci, and average numbers of alleles per locus, are given in Table 4, part (a) for each population, together with the inbreeding coefficient $F_{\text {IS. Obviously, }}$ two Chinese populations, DX and YJ, showed less polymorphism than the others. The other Chinese population, GG, showed a high level of genetic diversity compared with the tropical perennial populations (NE88, W1981, and W120). The annual population NE3 showed a low level of polymorphism, as expected. The inbreeding coefficient $F_{\text {IS }}$ was high in the annual NE3 population and low in the perennial NE88 and W120 populations.

$H_{\mathrm{T}}$ varied from $0.053(\mathrm{Acp} 6(\mathrm{t}))$ to $0.674(\mathrm{Amp} 2)$ and $H_{\mathrm{S}}$ from $0.012(E s t S(t))$ to 0.365 (Amp2) (Table 3). The parameter for population differentiation, $F_{\mathrm{ST}}$, ranged from $0.075(A c p 5(t))$ to $0.941(E s t S(t))$, with an average of 0.431 (Table 3). $F_{\mathrm{ST}}$ values tended to be high at Amp1, Cat1 and Est14, whose allele frequencies differentiated the Chinese populations from other populations. In addition, Est1 differentiating the annual NE3 from other populations and EstS(t) differentiating the two South Asian populations (W120 and W1981) from the others showed high $F_{\mathrm{ST}}$ values (Table 3 ). The genetic distances between populations (Table 5) tended to be small within the three regions - China, Thailand, and South Asia (India and Indonesia) - and large between different regions.

To elucidate the overall variations among and within populations, we evaluated the allozyme genotypes of all individuals by factor analysis. Although only $28.1 \%$ of total variation was extracted by the first and second factors, individuals belonging to different populations were plotted as forming respective clusters (Figure 3a). The first factor separated Chinese populations from other populations collected in tropical Asia. The second factor separated the Indonesian population (W1981) from all others. In contrast to the result achieved by the analysis of quantitative traits, perennial (NE88) and annual (NE3) populations from the same locality in Thailand were closely located.

\section{RFLP diversity}

From the 15 probe-enzyme combinations, a total of 17 polymorphic loci were detected. The allelic frequencies of RFLPs for the seven populations are shown in Table 6, together with their population parameters. Intrapopulation polymorphisms at the RFLP level were detected in all populations examined. As in the allozyme analysis, we found that the Chinese populations shared some common RFLPs (G1032, G249²) that were rarely found in other populations. This indicated that the Chinese populations tended to be genetically differentiated from the populations distributed in tropical countries.

Average gene diversity and other diversity parameters were calculated for each population (Table 4, part b). The annual population NE3 and the weakly perennial population YJ showed less polymorphism than some others. The inbreeding coefficient $F_{\mathrm{IS}}$ was high in the annual NE3 population and low in the perennial populations W1981 and W120. The population parameters $H_{\mathrm{T}}, H_{\mathrm{S}}$, and $F_{\mathrm{ST}}$ are shown in Table 6. $F_{\mathrm{ST}}$ values estimated for respective loci were widely distributed, ranging from 0.047 to 0.984 , with an average of 0.430 . The genetic distances calculated between the seven populations (Table 5) clearly showed genetic differentiation between the different regions.

RFLP data of all individuals were analyzed by factor analysis. Of the total variation, $35.7 \%$ was extracted by the first and second factors. Plants from the same population tended to form respective clusters reflecting their geographical distributions (Figure $3 b$ ). The pattern of variation proved to be essentially the same as that obtained from the allozyme data (Figure 3a): the first axis separated the Chinese populations and the others, and the second axis separated the south (India and Indonesia) and South-East Asian (Thailand) populations. 
Table 3 Allele frequencies at 27 polymorphic isozyme loci, and the population parameters $H_{\mathrm{T}}, H_{\mathrm{S}}$ and $F_{\mathrm{ST}}$

\begin{tabular}{|c|c|c|c|c|c|c|c|c|c|c|c|c|}
\hline \multirow[t]{2}{*}{ Locus/allele } & & \multirow[t]{2}{*}{ Chr. } & \multicolumn{7}{|c|}{ Population (no. of plants examined) } & \multirow[t]{2}{*}{$\mathrm{H}_{T}$} & \multirow[t]{2}{*}{$\mathrm{H}_{S}$} & \multirow[t]{2}{*}{$\mathrm{F}_{S T}$} \\
\hline & & & $D X(54)$ & $Y J(14)$ & GG (68) & NE3 (74) & NE88 (46) & W1981 (22) & W120 (14) & & & \\
\hline \multirow[t]{2}{*}{ Acp2 } & 1 & \multirow[t]{2}{*}{12} & 0.056 & 0.357 & 0.063 & 0.838 & 0.522 & \multirow[t]{2}{*}{1.000} & 0.357 & \multirow[t]{2}{*}{0.492} & \multirow[t]{2}{*}{0.239} & \multirow[t]{2}{*}{0.514} \\
\hline & 0 & & 0.944 & 0.643 & 0.937 & 0.162 & 0.478 & & 0.643 & & & \\
\hline \multirow[t]{2}{*}{ Acp3 } & 1 & \multirow[t]{2}{*}{$?$} & \multirow[t]{2}{*}{1.000} & \multirow[t]{2}{*}{1.000} & 0.810 & 0.189 & 0.326 & 0.545 & 0.214 & \multirow[t]{2}{*}{0.491} & 0.272 & 0.446 \\
\hline & 0 & & & & 0.190 & 0.811 & 0.674 & 0.455 & 0.786 & & & \\
\hline $\operatorname{Acp} 5(\mathrm{t})$ & 1 & ? & 0.981 & 1.000 & 0.956 & 1.000 & 1.000 & 0.818 & 1.000 & 0.053 & 0.049 & 0.075 \\
\hline & 2 & & 0.019 & & 0.044 & & & 0.182 & & & & \\
\hline $\operatorname{Acp} 6(\mathrm{t})$ & 1 & $?$ & 1.000 & 1.000 & 0.882 & 1.000 & 1.000 & 1.000 & 1.000 & 0.053 & 0.048 & 0.094 \\
\hline & 2 & & & & 0.118 & & & & & & & \\
\hline Amp1 & 1 & 2 & & & 0.044 & 0.459 & 0.957 & 0.500 & 0.429 & 0.596 & 0.226 & 0.621 \\
\hline & 2 & & & & & 0.541 & & & 0.072 & & & \\
\hline & 3 & & 1.000 & 1.000 & 0.956 & & 0.044 & 0.500 & 0.428 & & & \\
\hline Amp2 & 1 & 8 & 0.038 & & 0.559 & 0.264 & 0.250 & & 0.608 & 0.674 & 0.365 & 0.458 \\
\hline & 2 & & 0.963 & 1.000 & 0.426 & & 0.250 & 1.000 & 0.393 & & & \\
\hline & 3 & & & & 0.015 & 0.730 & 0.087 & & & & & \\
\hline & 4 & & & & & 0.006 & 0.413 & & & & & \\
\hline Amp3 & 1 & 6 & 0.981 & 1.000 & 0.470 & & 0.355 & 0.273 & 0.500 & 0.579 & 0.320 & 0.447 \\
\hline & 2 & & 0.019 & & 0.294 & 1.000 & 0.511 & 0.545 & 0.500 & & & \\
\hline & 0 & & & & 0.235 & & 0.044 & 0.136 & & & & \\
\hline Amp 7 & 1 & 6 & 0.093 & & 0.500 & & 0.174 & 0.182 & & 0.289 & 0.215 & 0.256 \\
\hline & 0 & & 0.907 & 1.000 & 0.500 & 1.000 & 0.826 & 0.818 & 1.000 & & & \\
\hline Cat1 & 1 & 6 & & & 0.964 & 1.000 & 0.978 & 1.000 & 0.750 & 0.381 & 0.045 & 0.882 \\
\hline & 2 & & 0.991 & 1.000 & 0.037 & & & & 0.250 & & & \\
\hline Est1 & 1 & 7 & 0.926 & 1.000 & 0.985 & & 0.870 & 0.818 & 1.000 & 0.424 & 0.090 & 0.788 \\
\hline & 0 & & 0.074 & & 0.015 & 1.000 & 0.130 & 0.182 & & & & \\
\hline Est2 & 1 & 6 & & 1.000 & 0.162 & 0.973 & 0.348 & 0.182 & 0.572 & 0.551 & 0.250 & 0.546 \\
\hline & 2 & & & & 0.074 & & 0.022 & 0.136 & & & & \\
\hline & 3 & & & & & 0.027 & 0.043 & & 0.285 & & & \\
\hline & 0 & & 1.000 & & 0.765 & & 0.587 & 0.682 & 0.143 & & & \\
\hline Est3 & 1 & 9 & 0.722 & 1.000 & 0.809 & & 0.761 & 0.545 & 0.286 & 0.496 & 0.260 & 0.476 \\
\hline & 2 & & 0.278 & & 0.191 & 1.000 & 0.239 & 0.455 & 0.714 & & & \\
\hline Est5 & 1 & 1 & 1.000 & 1.000 & 1.000 & 0.892 & 0.870 & 1.000 & 0.429 & 0.139 & 0.108 & 0.223 \\
\hline & 2 & & & & & 0.108 & 0.130 & & 0.572 & & & \\
\hline Est9 & 1 & 7 & 0.915 & 0.465 & 0.287 & & 0.011 & & 0.072 & 0.386 & 0.158 & 0.591 \\
\hline & 2 & & 0.085 & 0.536 & 0.713 & 1.000 & 0.989 & 1.000 & 0.929 & & & \\
\hline Est10 & 2 & 1 & & & 0.007 & 0.048 & 0.011 & 0.045 & 0.179 & 0.157 & 0.138 & 0.121 \\
\hline & 3 & & & & 0.155 & & & 0.273 & & & & \\
\hline & 4 & & 1.000 & 1.000 & 0.838 & 0.953 & 0.989 & 0.682 & 0.822 & & & \\
\hline Est12 & 1 & 9 & & & 0.250 & 0.689 & 0.261 & & 0.214 & 0.407 & 0.273 & 0.329 \\
\hline & 0 & & 1.000 & 1.000 & 0.750 & 0.311 & 0.739 & 1.000 & 0.786 & & & \\
\hline Est14 & 1 & $?$ & 0.981 & 1.000 & 0.588 & & & & & 0.464 & 0.120 & 0.741 \\
\hline & 2 & & 0.019 & & 0.412 & 1.000 & 1.000 & 1.000 & 1.000 & & & \\
\hline$E s t S(\mathrm{t})$ & 1 & $?$ & 1.000 & 1.000 & 1.000 & 1.000 & 1.000 & 0.091 & & 0.205 & 0.012 & 0.941 \\
\hline & 2 & & & & & & & 0.909 & 1.000 & & & \\
\hline $\operatorname{Mal5}(\mathrm{t})$ & 1 & $?$ & & & 0.029 & 0.563 & & & & 0.248 & 0.148 & 0.403 \\
\hline & 2 & & 1.000 & 1.000 & 0.971 & 0.437 & 1.000 & 1.000 & 1.000 & & & \\
\hline Mal6(t) & 1 & $?$ & & & 0.032 & 0.577 & & & & 0.254 & 0.139 & 0.453 \\
\hline & 2 & & 1.000 & 1.000 & 0.968 & 0.423 & 1.000 & 1.000 & 1.000 & & & \\
\hline$P g d 1$ & 1 & 11 & 1.000 & 1.000 & 0.956 & 0.541 & 0.163 & 0.786 & 0.571 & 0.431 & 0.242 & 0.439 \\
\hline & $\begin{array}{l}2 \\
3\end{array}$ & & & & $\begin{array}{l}0.037 \\
0.008\end{array}$ & 0.459 & 0.838 & 0.214 & $\begin{array}{l}0.286 \\
0.071\end{array}$ & & & \\
\hline
\end{tabular}

Table Continued... 
Table 3 (Continued)

\begin{tabular}{|c|c|c|c|c|c|c|c|c|c|c|c|c|}
\hline \multirow[t]{2}{*}{ Locus/allele } & & \multirow[t]{2}{*}{ Chr. } & \multicolumn{7}{|c|}{ Population (no. of plants examined) } & \multirow[t]{2}{*}{$\mathrm{H}_{T}$} & \multirow[t]{2}{*}{$\mathrm{H}_{S}$} & \multirow[t]{2}{*}{$\mathrm{F}_{S T}$} \\
\hline & & & $D X(54)$ & $Y J(14)$ & GG (68) & NE3 (74) & NE88 (46) & W1981 (22) & W120 (14) & & & \\
\hline \multirow[t]{3}{*}{$\operatorname{Pgd} 2$} & 1 & \multirow[t]{3}{*}{6} & 0.991 & \multirow[t]{3}{*}{1.000} & \multirow[t]{3}{*}{1.000} & \multirow[t]{3}{*}{1.000} & 0.956 & 0.387 & 0.929 & \multirow[t]{3}{*}{0.110} & \multirow[t]{3}{*}{0.060} & \multirow[t]{3}{*}{0.455} \\
\hline & 2 & & 0.010 & & & & 0.022 & 0.545 & 0.071 & & & \\
\hline & 3 & & & & & & 0.022 & 0.068 & & & & \\
\hline \multirow[t]{3}{*}{ Pgi1 } & 1 & \multirow[t]{3}{*}{3} & & & 0.044 & & 0.229 & & 0.107 & \multirow[t]{3}{*}{0.154} & \multirow[t]{3}{*}{0.140} & \multirow[t]{3}{*}{0.091} \\
\hline & 2 & & 0.907 & 1.000 & 0.941 & 1.000 & 0.772 & 0.864 & 0.893 & & & \\
\hline & 3 & & 0.093 & & 0.015 & & & 0.136 & & & & \\
\hline \multirow[t]{3}{*}{ Pgi2 } & 1 & \multirow[t]{3}{*}{6} & \multirow{3}{*}{$\begin{array}{l}0.907 \\
0.093\end{array}$} & \multirow[t]{3}{*}{1.000} & \multirow{3}{*}{$\begin{array}{l}0.948 \\
0.051\end{array}$} & \multirow{3}{*}{$\begin{array}{l}0.886 \\
0.115\end{array}$} & 0.554 & 0.364 & 1.000 & \multirow[t]{3}{*}{0.304} & \multirow[t]{3}{*}{0.220} & \multirow[t]{3}{*}{0.276} \\
\hline & 2 & & & & & & & & & & & \\
\hline & 4 & & & & & & 0.435 & 0.636 & & & & \\
\hline \multirow[t]{2}{*}{ Pgi3 } & 1 & \multirow[t]{2}{*}{$?$} & 0.981 & \multirow[t]{2}{*}{1.000} & 0.833 & \multirow[t]{2}{*}{1.000} & 0.891 & 0.864 & 1.000 & \multirow[t]{2}{*}{0.130} & 0.120 & 0.077 \\
\hline & 2 & & 0.019 & & 0.167 & & 0.109 & 0.136 & & & & \\
\hline Pox 2 & 1 & 12 & 0.722 & 1.000 & 0.833 & 1.000 & 0.767 & 1.000 & 0.667 & 0.244 & 0.219 & 0.102 \\
\hline & 2 & & 0.278 & & 0.136 & & 0.233 & & 0.333 & & & \\
\hline$S d h 1$ & 1 & 12 & & 0.107 & 0.051 & 1.000 & 1.000 & 0.205 & 0.321 & 0.578 & 0.124 & 0.785 \\
\hline & 2 & & 0.898 & 0.893 & 0.919 & & & & 0.678 & & & \\
\hline & 4 & & & & & & & 0.796 & & & & \\
\hline & 5 & & 0.102 & & 0.030 & & & & & & & \\
\hline
\end{tabular}

Table 4 Parameter values showing intrapopulation genetic diversity for the seven populations: (a) Allozymes (29 loci) and (b) RPLPs (17 loci), as estimated from allozyme and RFLP data

\begin{tabular}{|c|c|c|c|c|c|c|c|}
\hline \multirow[t]{2}{*}{ Parameter } & \multicolumn{7}{|c|}{ Population (propagating system ${ }^{\mathrm{a}}$ ) } \\
\hline & $D X(W P)$ & $Y J(W P)$ & $G G(W P)$ & $N E 3(A)$ & NE88 $(P)$ & W1981 (P) & W120 (P) \\
\hline \multicolumn{8}{|l|}{ (a) Allozymes (29 loci) } \\
\hline Average gene diversity & 0.074 & 0.040 & 0.204 & 0.136 & 0.214 & 0.215 & 0.252 \\
\hline Proportion of polymorphic loci & 0.55 & 0.10 & 0.83 & 0.41 & 0.69 & 0.55 & 0.59 \\
\hline Average no. of alleles/locus & 1.55 & 1.10 & 2.10 & 1.45 & 1.97 & 1.72 & 1.76 \\
\hline Inbreeding coefficient $\left(F_{\mathrm{IS}}\right)$ & 0.736 & 0.872 & 0.725 & 0.912 & 0.670 & 0.917 & 0.476 \\
\hline \multicolumn{8}{|l|}{ (b) RFLPs (17 loci) } \\
\hline Average gene diversity & 0.113 & 0.049 & 0.209 & 0.099 & 0.208 & 0.118 & 0.109 \\
\hline Proportion of polymorphic loci & 0.41 & 0.18 & 0.71 & 0.41 & 0.76 & 0.24 & 0.35 \\
\hline Average no. of alleles/locus & 1.53 & 1.18 & 2.12 & 1.53 & 2.06 & 1.41 & 1.47 \\
\hline Inbreeding coefficient $\left(F_{\mathrm{IS}}\right)$ & 0.477 & 0.343 & 0.487 & 0.818 & 0.621 & 0.310 & 0.386 \\
\hline
\end{tabular}

aWP: weakly perennial; P: perennial; A: annual.

Table 5 Genetic distances between the seven populations, computed from allozyme (above diagonal) and RFLP (below diagonal) data

\begin{tabular}{|c|c|c|c|c|c|c|c|}
\hline \multirow[t]{2}{*}{ Population } & \multicolumn{3}{|c|}{ China } & \multicolumn{2}{|c|}{ Thailand } & \multirow{2}{*}{$\frac{\text { Indonesia }}{\text { W1981 }}$} & \multirow{2}{*}{$\frac{\text { India }}{W 120}$} \\
\hline & $D X$ & $Y J$ & GG & NE3 & NE88 & & \\
\hline DX (China) & & 0.166 & 0.109 & 0.681 & 0.391 & 0.476 & 0.352 \\
\hline YJ (China) & 0.141 & & 0.196 & 0.377 & 0.343 & 0.444 & 0.285 \\
\hline GG (China) & 0.107 & 0.140 & & 0.435 & 0.207 & 0.328 & 0.215 \\
\hline NE3 (Thailand) & 0.201 & 0.240 & 0.159 & & 0.217 & 0.411 & 0.289 \\
\hline NE88 (Thailand) & 0.227 & 0.243 & 0.167 & 0.049 & & 0.224 & 0.204 \\
\hline W1981 (Indonesia) & 0.249 & 0.287 & 0.403 & 0.250 & 0.273 & & 0.220 \\
\hline W120 (India) & 0.326 & 0.377 & 0.546 & 0.392 & 0.294 & 0.260 & \\
\hline
\end{tabular}

\section{Discussion}

In O. rufipogon, annual types are predominantly inbreeding and perennial types are partly outbreeding (Oka and Morishima, 1967; Morishima and Barbier, 1990). Therefore, intrapopulation diversity is generally lower in annual types than in perennial types (Barbier, 1989; Morishima and Barbier, 1990). In our study, the annual population NE3 was less diversified and had a high inbreeding coefficient, as expected. In contrast, the partly outbreeding perennial populations were found to preserve variable amounts of genetic diversity. It is difficult 
a

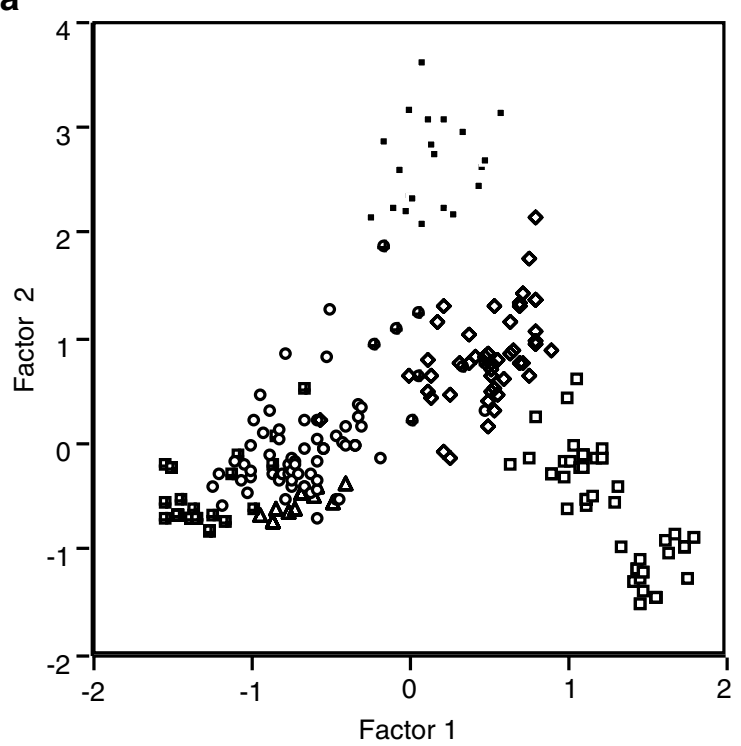

b

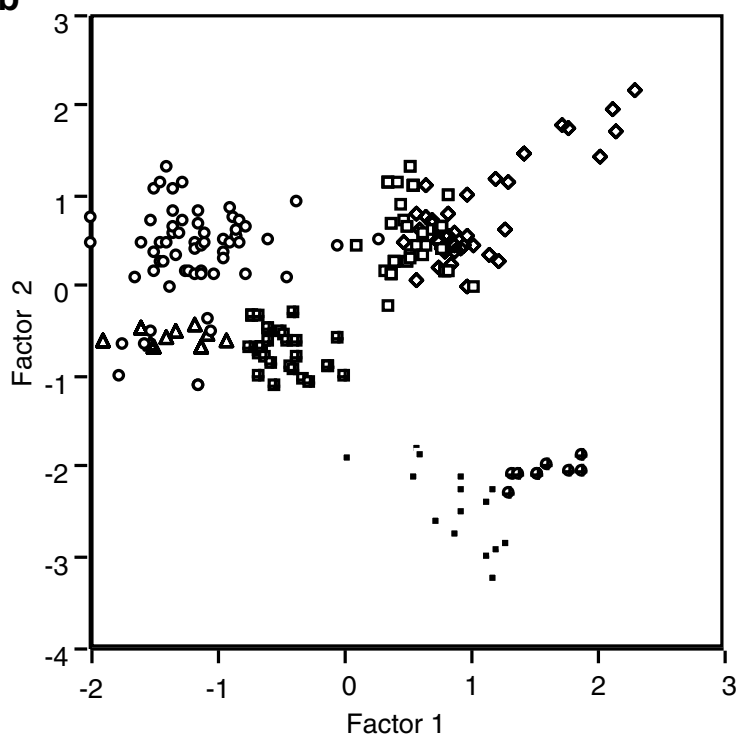

- DX(China) $\Delta Y J($ China) $0 \mathrm{GG}($ China) a NE3(Thailand)

$\diamond$ NE88(Thailand) - W1981(Indonesia) • W120(India)

Figure 3 Scatter diagram of the plants belonging to seven populations on the first and second factor scores, based on allozymes (a) and RFLPs (b).

to explain this intrapopulation genetic diversity only in terms of breeding systems, because we know little about the long-term evolutionary history of each population. The large amount of genetic variability found in the Chinese population GG is most probably due to the effect of introgression from cultivated rice growing nearby: this was evident from the fact that the GG population contained alleles such as Est $2^{2}$ and Est10 ${ }^{2}$, which are rare in Chinese wild rice but are carried by cultivated rice. The relatively low diversity of YJ is probably because $\mathrm{YJ}$ is an isolated peripheral population. Thus, the amount of genetic diversity within the populations that we observed was undoubtedly influenced by both the breeding system and the evolutionary history of each population.

A major difference in quantitative traits among our populations was ecotype differentiation towards either perennial or annual types (Figure 2), as has been repeatedly argued in this species (Oka and Morishima, 1967; Sano and Morishima, 1982, Morishima et al, 1984). As all of the plants we analyzed were grown in a common environment, we consider that the observed differentiation in quantitative traits has at least in part a genetic basis. This variation in pattern reflects the result of adaptive differentiation in life-history traits that has occurred within this species in response to different habitat conditions (Morishima et al, 1984).

In contrast, population differentiation revealed by allozyme and RFLP analysis more likely effects geographic variation due to genetic isolation (Figure 3). The approximate geographical distances among study sites were roughly estimated from the map of Asia. Rank correlations were calculated between the geographical distance matrix and two genetic distance matrices (Table 5). The rank correlation was $r=0.529(P<0.05)$ with the allozyme matrix, and $r=0.660(P<0.01)$ with the RFLP matrix. These significant correlations are probably due to increasing genetic distance with geographical distance.

The results of the allozyme and RFLP studies both suggest genetic differentiation among South Chinese (temperate) populations and South-East Asian (tropical) populations. This agrees with the results of our earlier allozyme study, which was based on a larger number of accessions collected over a broad area of Asia (Cai et al, 1996). Assuming that these allozymes and RFLPs are neutral, we can suggest that this genetic variation has resulted from long-range dispersal of this wild rice species, followed by geographical isolation (isolation by distance model, Slatkin, 1993) rather than as a result of adaptation to local environmental conditions. However, it cannot be ruled out that molecular markers may vary in relation to selection processes. Even if they themselves are neutral they can vary due to natural selection as a result of hitchhiking. Therefore, it is difficult to fully estimate the relative importance of selective and neutral processes in causing geographical differentiation. Raybould et al $(1996,1997)$ compared RFLPs and allozymes in their study on sea beet populations and found that isolation by distance was evident in RFLPs but not in allozymes. Latta and Mitton (1997) observed in limber pine populations that RAPD analysis showed a higher degree of divergence than allozymes. We failed to find marked differences between allozyme and RFLP markers in terms of differentiation pattern and population structure.

The measure of population differentiation, $F_{\mathrm{ST}}$, can be influenced by various factors such as effective population size, genetic drift, migration rate (mating system), mutation rate, and selection (Podolsky and Holtsford, 1995). According to Hamrick and Godt (1990), who collected a large amount of information on allozyme diversity, mean $F_{\mathrm{ST}}\left(G_{\mathrm{ST}}\right)$ is 0.197 for outcrossers, 0.084 for woody perennials, 0.099 for wind-pollinated species, 0.233 for perennial herbaceous species, and 0.397 for annuals. In O. rufipogon, Gao et al (2000) obtained $F_{\mathrm{ST}}=0.310$ for Chinese perennial populations. From studies of Indian and Thai populations, 
Table 6 Allelic frequencies of RFLPs for the seven populations, and the population parameters $H_{\mathrm{T}}, H_{\mathrm{S}}$ and $F_{\mathrm{ST}}$

\begin{tabular}{|c|c|c|c|c|c|c|c|c|c|c|c|c|}
\hline \multirow[t]{2}{*}{ Locus/allele } & \multirow[t]{2}{*}{ Chr. } & & \multicolumn{7}{|c|}{ Population (no. of plants examined) } & \multicolumn{3}{|c|}{ Population parameter } \\
\hline & & & DX (40) & YJ (14) & GG (62) & NE3 (73) & NE88 (39) & W1981 (16) & W120 (9) & $\mathrm{H}_{T}$ & $\mathrm{H}_{S}$ & $\mathrm{~F}_{S T}$ \\
\hline \multirow[t]{5}{*}{ RG214 } & 1 & 4 & 1.000 & 1.000 & 0.645 & 0.822 & 0.564 & 0.531 & 0.889 & 0.396 & 0.324 & 0.181 \\
\hline & 2 & & & & 0.008 & 0.171 & 0.051 & 0.063 & & & & \\
\hline & 3 & & & & & 0.007 & 0.064 & & 0.111 & & & \\
\hline & 5 & & & & 0.347 & & 0.321 & 0.156 & & & & \\
\hline & 6 & & & & & & & 0.250 & & & & \\
\hline \multirow[t]{2}{*}{ RG181 } & 1 & 8 & 1.000 & 0.857 & 1.000 & 1.000 & 0.744 & 1.000 & 0.444 & 0.125 & 0.085 & 0.321 \\
\hline & 2 & & & 0.143 & & & 0.256 & & 0.556 & & & \\
\hline \multirow[t]{6}{*}{ RZ792 } & 1 & 9 & 0.950 & & 0.282 & 0.897 & 0.423 & 0.281 & 0.056 & 0.632 & 0.282 & 0.554 \\
\hline & 2 & & 0.050 & & 0.024 & 0.014 & 0.013 & 0.719 & & & & \\
\hline & 3 & & & & 0.363 & 0.089 & & & & & & \\
\hline & 4 & & & & & & 0.526 & & 0.778 & & & \\
\hline & 5 & & & 1.000 & 0.331 & & 0.038 & & 0.111 & & & \\
\hline & 6 & & & & & & & & 0.056 & & & \\
\hline \multirow[t]{2}{*}{ RZ141 } & 1 & 11 & 1.000 & 1.000 & 1.000 & 0.986 & 1.000 & 1.000 & & 0.076 & 0.001 & 0.984 \\
\hline & 2 & & & & & 0.014 & & & 1.000 & & & \\
\hline \multirow[t]{3}{*}{ BCD126 } & 1 & 5 & 1.000 & 0.929 & 0.927 & 1.000 & 1.000 & 1.000 & 1.000 & 0.043 & 0.041 & 0.047 \\
\hline & 3 & & & & 0.040 & & & & & & & \\
\hline & 4 & & & 0.071 & 0.032 & & & & & & & \\
\hline \multirow[t]{4}{*}{ RZ561 } & 1 & 1 & 0.663 & 1.000 & 0.734 & 1.000 & 0.577 & 1.000 & 0.111 & 0.360 & 0.199 & 0.446 \\
\hline & 2 & & 0.313 & & 0.048 & & 0.372 & & 0.889 & & & \\
\hline & 3 & & 0.013 & & 0.081 & & 0.051 & & & & & \\
\hline & 4 & & 0.013 & & 0.137 & & & & & & & \\
\hline \multirow[t]{2}{*}{ CDO393 } & 1 & 5 & 1.000 & 1.000 & 0.879 & 1.000 & 0.897 & 0.438 & 1.000 & 0.125 & 0.073 & 0.418 \\
\hline & 2 & & & & 0.121 & & 0.013 & 0.563 & & & & \\
\hline \multirow[t]{2}{*}{ CDO127 } & 1 & 11 or 12 & 1.000 & 1.000 & 0.565 & 0.61 & 0.654 & 1.000 & 1.000 & 0.397 & 0.289 & 0.272 \\
\hline & 2 & & & & 0.435 & 0.39 & 0.346 & & & & & \\
\hline \multirow[t]{2}{*}{ RG345 } & 1 & 1 & 1.000 & 1.000 & 0.935 & 1.000 & 1.000 & 1.000 & 1.000 & 0.031 & 0.029 & 0.056 \\
\hline & 2 & & & & 0.065 & & & & & & & \\
\hline \multirow[t]{2}{*}{ BCD855 } & 1 & 7 & 1.000 & 1.000 & 1.000 & 1.000 & 0.769 & 1.000 & 1.000 & 0.069 & 0.055 & 0.205 \\
\hline & 2 & & & & & & 0.231 & & & & & \\
\hline \multirow[t]{3}{*}{ G103 } & 1 & 9 & & 0.643 & 0.032 & 0.986 & 0.974 & 1.000 & 0.944 & 0.495 & 0.12 & 0.758 \\
\hline & 2 & & 0.988 & 0.357 & 0.944 & 0.014 & 0.026 & & 0.056 & & & \\
\hline & 3 & & 0.013 & & 0.024 & & & & & & & \\
\hline \multirow[t]{2}{*}{ G249 } & 1 & 3 & 0.238 & & 0.194 & 1.000 & 1.000 & 1.000 & 1.000 & 0.468 & 0.097 & 0.793 \\
\hline & 2 & & 0.763 & 1.000 & 0.806 & & & & & & & \\
\hline \multirow[t]{3}{*}{ G187 } & 1 & 8 & 0.025 & & 0.048 & 0.329 & 0.051 & 0.063 & 0.389 & 0.304 & 0.192 & 0.368 \\
\hline & 2 & & 0.975 & 1.000 & 0.952 & 0.671 & 0.949 & 0.281 & 0.611 & & & \\
\hline & 3 & & & & & & & 0.656 & & & & \\
\hline \multirow[t]{2}{*}{ G89-2a } & 1 & 1 & 1.000 & 1.000 & 0.790 & 1.000 & 0.974 & 1.000 & 1.000 & 0.105 & 0.088 & 0.161 \\
\hline & 2 & & & & 0.210 & & 0.026 & & & & & \\
\hline \multirow[t]{2}{*}{ G89-2b } & 1 & $10 ?$ & & & & 0.137 & 0.179 & & & 0.125 & 0.110 & 0.121 \\
\hline & 2 & & 1.000 & 1.000 & 1.000 & 0.863 & 0.821 & 1.000 & 1.000 & & & \\
\hline G282a & 1 & 4 & 0.625 & & & & 0.051 & 1.000 & 1.000 & 0.327 & 0.056 & 0.829 \\
\hline & 2 & & 0.375 & 1.000 & 1.000 & 1.000 & 0.949 & & & & & \\
\hline $\mathrm{G} 282 \mathrm{~b}$ & 1 & 4 & 0.350 & & 0.903 & 1.000 & 0.949 & & & 0.411 & 0.086 & 0.791 \\
\hline & 2 & & 0.650 & 1.000 & 0.097 & & 0.051 & 1.000 & 1.000 & & & \\
\hline
\end{tabular}

Morishima and Barbier (1990) reported 0.396 for perennials and 0.600 for annuals. The mean $F_{\mathrm{ST}}$ value obtained in our present study was 0.431 in allozymes and 0.430 in RFLPs.
The comparison of population differentiation parameters for different classes of traits or markers is a useful tool in the analysis of the causes of population variation. To describe differentiation among populations, quantita- 
tive traits have lower resolving power than allozymes and RFLPs in our present study, although $P_{\mathrm{ST}}$ is not strictly identical to $F_{\mathrm{ST}}$. Allozyme analysis showed a similar level of resolution to RFLPs, although the latter technique is much more expensive and time-consuming. Heterogeneity of $F_{\mathrm{ST}}$ values among loci was another feature of our study (Tables 3 and 6 ). In past studies, $F_{\mathrm{ST}}$ values estimated for allozymes have been relatively homogeneous across loci and lower than $F_{\mathrm{ST}}$ for quantitative traits (Podolsky and Holtsford, 1995) or RAPD (Latta and Mitton, 1997). It is difficult to conclude whether the heterogeneity of $F_{\mathrm{ST}}$ values that we found among loci is a reflection of a stochastic process, or whether indirect selection through hitchhiking is involved.

\section{Acknowledgements}

We thank Dr SR McCouch (Cornell University, Ithaca, NY, USA) and Dr T Sasaki (Rice Genome Program, STAFF Institute, Tsukuba, Japan) for their kindly providing the RFLP probes. We also thank two anonymous reviewers for their valuable comments on the paper.

\section{References}

Barbier P (1989). Genetic variation and ecotype differentiation in the wild rice species Oryza rufipogon.II Influence of the mating system and life-history traits on the genetic structure of populations. Jpn J Genet 64: 273-285.

Bonnin I, Prosperi JM, Olivieri I (1996). Genetic markers and quantitative genetic variation in Medicago truncatula (Leguminosae): a comparative analysis of population structure. Genetics 143: 1795-1805.

Cai HW, Wang XK, Cheng KS, Zhang YZ (1992). Classification of Asian rices by esterase allozymes. Southwest China J Agric Sci 5: 19-23 (in Chinese).

Cai HW, Wang XK, Morishima H (1996). Geographical variation of O. rufipogon with reference to perennial-annual differentiation. Rice Genet Newslett 13: 67-69.

Gao LZ, Ge S, Hong DY (2000). Allozyme variation and population genetic structure of common wild rice Oryza rufipogon Griff. in China. Theor Appl Genet 101: 4-502.

Gao LZ, Schaal BA, Zhang CH, Jia JZ, Dong DY (2002). Assessment of population genetic structure in common wild rice Oryza rufipogon Griff. using microsatellite and allozyme markers. Theor Appl Genet 106: 173-180.

Ge S, Oliveira GCX, Schaal BA, Gao LZ, Hong DY (1999). RAPD variation within and between natural populations of the wild rice Oryza rufipogon from China and Brazil. Heredity 82: 638-644.

Hamrick JL, Godt MJW (1990). Allozyme diversity in plant species. In: Brown AHD, Clegg MT, Kahler AL (eds) Plant Populations Genetics, Breeding and Genetic Resources. Sinauer: Sunderland, MAS, pp 43-63.
Ishikawa R, Morishima H, Mori K, Kinoshita T (1989). Chromosomal analysis of isozyme loci and the allelic expression at cellular level in rice. J Fac Agric Hokkaido Univ 64: 85-98.

Karl SA, Avise JC (1992). Balancing selection at allozyme loci in oysters; implications from nuclear RFLPs. Science 256: 100-102.

Kimura M (1968). Evolutionary rate at the molecular level. Nature 217: 624-626.

Koehn RK, Zera AJ, Hall G (1983). Enzyme polymorphism and natural selection. In : Nei M, Koehn RK ( eds ) Evolution of Genes and Proteins. Sinauer: Sunderland, MA, pp 115-136.

Latta RG, Mitton JB (1997). A comparison of population differentiation across four classes of gene marker in limber pine (Pinus flexilis James). Genetics 146: 1153-1163.

McCouch SR, Kochert G, Yu ZH, Wang ZY, Khush GS, Coffman WR, et al (1988). Molecular mapping of rice chromosomes. Theor Appl Genet 76: 815-829.

Morishima H, Barbier P (1990). Mating system and genetic structure of natural populations in wild rice, Oryza rufipogon. Plant Species Biol 5: 31-39.

Morishima H, Oka HI (1970). A survey of genetic variations in the populations of wild Oryza species and their cultivated relatives. Jpn J Genet 45: 371-385.

Morishima H, Sano Y, Oka HI (1984). Differentiation of perennial and annual populations of the Asian wild rice Oryza perennis. Plant Syst Evol 144: 119-135.

Nei M (1972). Genetic distance between populations. Am Nat 106: 283-292.

Oka HI (1988). Origin of Cultivated Rice. Japanese Scientific Society Press: Tokyo/Elsevier, Amsterdam, pp 254.

Oka HI, Morishima H (1967). Variation in the breeding systems of a wild rice, Oryza perennis. Evolution 21: 249-258.

Podolsky RH, Holtsford TP (1995). Population structure of morphological traits in Clarkia dudleyana I. Comparison of Fst between allozymes and morphological traits. Genetics 140: 733-744.

Raybould AF, Mogg RJ, Clarke RT (1996). The genetic structure of Beta vulgaris sp. maritima (sea beet) populations: RFLPs and allozymes show different patterns of gene flow. Heredity 77: $245-250$.

Raybould AF, Mogg RJ, Gliddon CJ (1997). The genetic structure of Beta vulgaris ssp. maritima (sea beet) populations II. Differences in gene flow estimated from RFLP and isozyme loci are habitat-specific. Heredity 78: 532-538.

Reed DH, Frankham R (2001). How closely correlated are molecular and quantitative measures of genetic variation? A meta-analysis. Evolution 55: 1095-1103.

Sano Y, Morishima H (1982). Variation in resource allocation and adaptive strategy of a wild rice, Oryza perennis Moench. Bot Gaz 143: 518-523.

Second G (1982). Origin of the genic diversity of cultivated rice (Oryza spp.): study of the polymorphism scored at 40 isozyme loci. Jpn J Genet 57: 25-57.

Second G (1985). Evolutionary relationships in the Sativa group of Oryza based on isozyme data. Genet Sel Evol 17: 89-114.

Slatkin M (1993). Isolation by distance in equilibrium and nonequilibrium populations. Evolution 47: 264-279. 